\title{
Assessment of sexual harassment and associated factors among grade 9-12 female students at schools in ambo district, Oromia national regional state, Ethiopia
}

\author{
Ejeta Eshetu \\ Ambo University, College of Medicine and Health Sciences, Ambo, Ethiopia
}

Email address:

eejeta@yahoo.com

To cite this article:

Ejeta Eshetu. Assessment of Sexual Harassment and Associated Factors among Grade 9-12 Female Students at Schools in Ambo District, Oromia National Regional State, Ethiopia. Science Journal of Public Health. Vol. 3, No. 1, 2015, pp. 97-100.

doi: $10.11648 /$ j.sjph.20150301.27

\begin{abstract}
Research question: What is the prevalence of the sexual harassment and various factors influencing it in school? Setting: Secondary and preparatory school of Ambo district. Study Design: Institutional based cross-sectional study design with qualitative study design. Participant: All female students from grade nine to twelve found in Ambo Secondary and Preparatory School $(n=414)$. Methodology: out of 1631 regular female students in the Schools, 414 were selected by stratified sampling technique. Data were collected using structured pre tested questionnaires with Focus group discussion guide and entered into EPI Info then exported to SPSS for analysis. Result: Prevalence of sexual harassment among female students in school through their school life and past twelve months were 147(35.5\%) and 138(33.3\%), respectively. Having peer relationship problem, parents not living together and had ever chewed khat were statistically significant with last twelve months sexual harassment in school. Therefore, ongoing awareness creation, preventive measure, and law enact are essential.
\end{abstract}

Keywords: Sexual Harassment, Students in School, Female, Ambo

\section{Introduction}

Sexual harassment is typically defined as a form of unwanted or unwelcome sexual attention and is considered as a form of gender-based violence. If it is among youth encompasses acts that are sufficiently severe, persistent, or pervasive to limit a student's ability to participate in or benefit from an education program or activity, or to create a hostile or abusive educational environment.

Harassment and discrimination to female in school are often unnoticed types of violence that frequently makes it difficult for affected individuals and groups to realize their full capacity (1).

According to study conducted in Jimma zone on violence against school girl the major harasser and other unwelcome sexual advances and hostile environments against the school girls were $50.7 \%$ of street wanderers, followed by $31.29 \%$ of school boys and $17.4 \%$ of teachers (2).

The objectives of this study to assess the prevalence and factors associated with sexual harassment at school among grade nine to twelve female students in Ambo Secondary and Preparatory Schools in Ambo District.

\section{Methods and Materials}

School based cross-sectional study design supplemented with qualitative research method was conducted in Ambo district in 2012/13.

A stratified sampling technique with simple random sampling was employed for the selection of the sampling units. A structured pre-tested questionnaire was used to collect the data. The data were entered into EPI Info version 3.5 and exported to SPSS version 16 for analysis.

Two Focus Group Discussions were conducted using FGD guide questions during discussion. Members of FGD were selected using purposive sampling technique.

\section{Observations}

A total of 414 female students were included in the study from which $329(79.5 \%)$ were from urban. The mean age of respondents was $(17.17+1.67$ years $)$ with an age range of 1425 years. 
Table 1. Socio-demographic characteristics of Ambo Secondary and Preparatory School female Students, Ethiopia, April, 2012, $(n=414)$.

\begin{tabular}{ll|l}
\hline Variables & Number & Percentage (\%) \\
\hline Age & & \\
$<15$ & 61 & 14.7 \\
$15-19$ & 311 & 75.1 \\
$>19$ & 42 & 10.1 \\
Residence & & \\
Urban & 329 & 79.5 \\
Rural & 85 & 20.5 \\
Religion & & \\
Orthodox & 208 & 50 \\
Protestant & 193 & 46.4 \\
Muslim & 13 & 2.7 \\
Marital status & & \\
Unmarried & 375 & 90.6 \\
Married & 39 & 9.4 \\
Current living arrangement & & \\
With both parents & 209 & 50.5 \\
With relative & 84 & 20.3 \\
Alone & 59 & 14.3 \\
With Mother or Father only & 39 & 9.4 \\
With Husband/partner & 23 & 5.6 \\
Total & 414 & $100 \%$ \\
\hline
\end{tabular}

\subsection{Parental Socio-Economic Characteristics}

Two hundred and ninety one participants $(70.3 \%)$ reported that their parents are living together whereas $123(29.7 \%)$ reported that they are separated.

\subsection{History of Respondents'Substances Use}

Drinking alcohol, chewing khat and smoking cigarette/tobacco ever in their life were reported by 79 $(19.1 \%), 43(10.4 \%)$ and $8(1.9 \%)$ respondents, respectively. Regarding to the frequency of substances use 28 (35\%) and $27(62.8 \%)$ of respondents were using alcohol and khat frequently, respectively.

\subsection{Prevalence of Sexual Harassment}

Among the total 414 female students 147 (35.5\%) and 138 $(33.3 \%)$ of them experienced sexual harassment throughout school life and in the last twelve months in the schools, respectively.

Out of $138(33.3 \%)$ who reported sexual harassment in the last twelve months, $66(47.8 \%)$ were verbal and $49(35.5 \%)$ were physical sexual harassments. Among female students who experienced sexual harassment in the last twelve months, $84(60.9 \%)$ feared harassment in the school and $54(39.1 \%)$ never feared being sexual harassed in the school.

\subsection{Perpetrator of Sexual Harassment}

The main perpetrators of twelve months sexual harassment in school were male students $80(58 \%)$ (Figure 1).

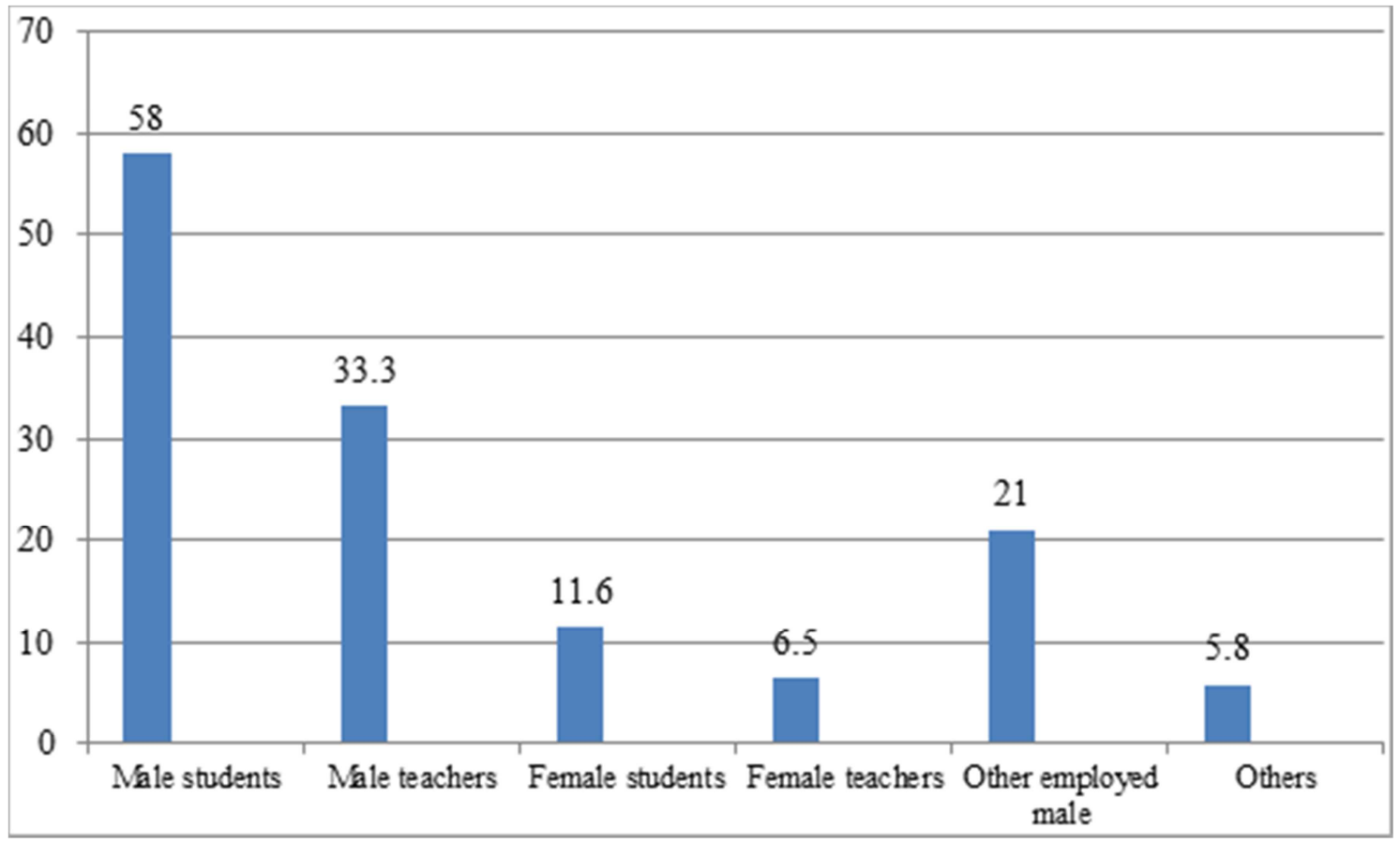

Note-Percentage do not add up together because multiple response possible

Figure 1. Distribution of sexual harasser on female students in Schools, April, 2012.

\subsection{Reported Place of Sexual Harassment in School}

Sexual harassment mostly occurred in the schools compound 68 (49.3\%), followed by in classroom 57 (41.3\%), and in the office 27 (19.7\%). Similar place mentioned during focus group discussion.

\subsection{Experiences of Unwanted Sexual Behaviour in the School}

The most common unwanted sexual behaviors that were experienced by sexual harassed female students in the schools were repeatedly told sexual stories or jokes 70 
(50.7\%), attempts to comment on sexual life $65(47 \%)$, ask for date, drink or dinner though the answer "no" 64 (46.4\%), attempt to established romantic relationship despite efforts of discourage $63(45.7 \%)$ and made offensive remarks about appearance or body 61 (44.2\%) (Table 2$)$

Table 2. Unwanted sexual behaviours female students experienced in Schools in the last twelve months, April, 2012(N=138).

\begin{tabular}{l|c|c}
\hline Experiences of unwanted sexual behaviour & No & Percentage \\
\hline $\begin{array}{l}\text { Repeatedly told sexual stories or jokes that were } \\
\text { offensive }\end{array}$ & 70 & 50.7 \\
$\begin{array}{l}\text { Made unwanted attempts to draw into } \\
\text { discussion/comment of sexual matter and life }\end{array}$ & 65 & 47.0 \\
$\begin{array}{l}\text { Made offensive remarks about the appearance the } \\
\text { body }\end{array}$ & 61 & 44.2 \\
$\begin{array}{l}\text { Made gestures of sexual way that embarrassed } \\
\text { Continued to ask for date, drink or dinner though the }\end{array}$ & 33 & 24.0 \\
$\begin{array}{l}\text { answer "no" } \\
\text { Made unwanted attempt to established romantic } \\
\text { relationship despite efforts of discouragement }\end{array}$ & 63 & 46.4 \\
\hline
\end{tabular}

\begin{tabular}{|c|c|c|}
\hline Experiences of unwanted sexual behaviour & No & Percentage \\
\hline Touch in a way that made feel uncomfortable & 40 & 29.0 \\
\hline Made unwanted attempt to fondle or kiss & 30 & 21.7 \\
\hline $\begin{array}{l}\text { Implied faster better treatment if sexually } \\
\text { cooperative }\end{array}$ & 46 & 33.3 \\
\hline $\begin{array}{l}\text { Made feel bride with sort of reward to engage in } \\
\text { sexual behavior }\end{array}$ & 40 & 29.0 \\
\hline Treated badly for refusing to have sex & 38 & 27.5 \\
\hline $\begin{array}{l}\text { Made feel threatened with sort of retaliation for not } \\
\text { being sexually cooperative }\end{array}$ & 36 & 26.0 \\
\hline
\end{tabular}

Note: Percentage does not add up to $100 \%$ because multiple responses were possible.

\subsection{Factors Associated with Sexual Harassment}

In multivariate logistic regression analysis, sexual harassment was associated significantly and independently with residence, marital status, having peer relationship problem in school, parents living together and ever khat chewing only (Table 3 ).

Table 3. Multivariate logistic regression analysis for potential factors associated with twelve months sexual harassment among female students grade 9-12 in School in Ambo District, April, 2012(n=414).

\begin{tabular}{|c|c|c|c|c|}
\hline \multirow{2}{*}{ Variables } & \multicolumn{2}{|c|}{ sexual harassment } & \multirow{2}{*}{$\begin{array}{l}\text { Crude OR } \\
(95 \% \text { CI) }\end{array}$} & \multirow{2}{*}{$\begin{array}{l}\text { Adjusted OR } \\
(95 \% \text { CI })\end{array}$} \\
\hline & Yes(n) & No(n) & & \\
\hline \multicolumn{5}{|l|}{ Residence } \\
\hline Urban & 101 & 228 & $0.575(0.353,0.937)^{*}$ & $0.577(0.343,0.971)^{*}$ \\
\hline Rural & 37 & 48 & 1 & 1 \\
\hline \multicolumn{5}{|l|}{ Marital status } \\
\hline Unmarried & 131 & 244 & $2.454(1.054,5.713)^{*}$ & $2.855(1.175,6.94)^{*}$ \\
\hline Married & 7 & 32 & 1 & 1 \\
\hline Yes & 33 & 37 & $2.03(1.204,3.423)^{* *}$ & $0.642(0.356,1.156)$ \\
\hline No & 105 & 239 & 1 & 1 \\
\hline \multicolumn{5}{|c|}{ Peer relationship problem } \\
\hline Yes & 43 & 34 & $3.222(1.937,5.357)^{* * *}$ & $2.839(1.668,4.834)^{* * *}$ \\
\hline No & 95 & 242 & 1 & 1 \\
\hline \multicolumn{5}{|l|}{ Parents living together } \\
\hline Yes & 88 & 205 & 1 & 1 \\
\hline \multicolumn{5}{|l|}{ Currently living with } \\
\hline Alone & 33 & 26 & 1 & 1 \\
\hline Both parents & 57 & 152 & $0.295(0.16,0.56)^{* * *}$ & $0.53(0.267,1.052)$ \\
\hline Husband/partner & 4 & 19 & $0.166(0.05,0.548)^{* *}$ & $0.37(0.073,1.883)$ \\
\hline Mother/Father only & 12 & 27 & $0.35(0.149,0.821)^{*}$ & $0.498(0.199,1.249)$ \\
\hline Relative & 32 & 52 & $0.485(0.248,0.954)^{*}$ & $0.718(0.342,1.508)$ \\
\hline \multicolumn{5}{|l|}{ Khat chewing } \\
\hline Yes & 25 & 18 & $3.171(1.664,6.044) * * *$ & $2.729(1.347,5.53)^{* *}$ \\
\hline No & 113 & 258 & 1 & 1 \\
\hline \multicolumn{5}{|c|}{ Ever alcohol consumption } \\
\hline Yes & 35 & 44 & $1.792(1.086,2.957)^{*}$ & $1.294(0.639,2.619)$ \\
\hline No & 103 & 232 & 1 & 1 \\
\hline
\end{tabular}

*Significant at $\mathrm{p}<0.05, * *$ Significant at $\mathrm{p}<0.01, * * *$ Significant at $\mathrm{p}<0.001$

During focus group discussion members of discussant were mention being assertive (confident) female students, being academically outstanding female students, being cosmetic and immodest dressing style is some of the factors associated with harassment.

\section{Discussion}

The prevalence of sexual harassment among female students was $35.5 \%$ throughout their schools life and $33.3 \%$ in the last twelve months at the schools. The prevalence of twelve months sexual harassment in the schools was higher than the findings of study conducted in Canada where the prevalence rate was $23 \%(5)$. However, it is lower than the studies conducted in 2005 in Sweden(3).

A study conducted in Kenya on school girls revealed that prevalence of sexual harassment in school was $60 \%$ which is inconsistent with the corresponding values of this findings (6). The twelve months sexual harassment prevalence of the study was not in line with the studies conducted in 2008 in 
Addis Ababa school, in 2003 in Dabat, and in Jimma Zone high school female students where the prevalence revealed that $74 \%, 44 \%$ and $73.4 \%$, respectively $(2,4-5)$. One of the main possible reasons causing the different number of sexual harassment cases could be similar unwelcome sexual advance considered differently in different setting and in different researches.

In this study, the common types of sexual harassment in the schools were verbal sexual harassment and which were comparable with $49.8 \%$ and $31.1 \%$ from the study conducted in Jimma zone on high school female students (2).

Our study identified being unmarried, having a parents not living together, Khat chewing

Living in urban and having unfriendly relationship with peer to be significant associated with sexual harassment.

\section{Conclusions}

The study identified high prevalence of sexual harassment at school among female students and factors such as not have parents living together, khat chewing, unmarried, peer relationship problem and living in urban showed statistical significant association with sexual harassment at school. Therefore, for improvement school environment ongoing awareness creation, preventive measure, participatory intervention, counselling, and awareness program for female students.

\section{Acknowledgement}

We would like to thank University of Gondar for funding this study.

\section{References}

[1] Paludi, M. 1997. Sexual harassment in schools in In: W. O'Donohue (Ed.). Sexual Harassment: Theory, research, and treatment. Needham Heights: Allyn \& Bacon, pp. 225-250.

[2] Mokonnen, G. \& Asreash, D. 2007. sexual violence against schoolgirls in jimma zone: prevalence, pattern and consequence. Ethiopian Journal of Eduction \& Science, 2(2).

[3] Eva, W. \& Menckel, E. 2005. Perceptions of sexual harassment in Swedish high schools: experiences and schoolenvironment problems. European Journal of Public Health, 15(1), pp.78-85.
[4] Mulugeta, E., Kassaye, M. \& Berhane, Y. 1998. Prevalence and outcomes of sexual violence among high school students. Ethiopian Medical Journaal, 36(3), p.47.

[5] Fitaw, Y. et al. 2005. Gender-besed violence among high school students in north west Ethiopia. Ethiop Medical Journal, 43(4), pp.215-221.

[6] Sara JR 2009. Sexual Abuse of School Age Children: Evidence from Kenya. Journal of International Cooperation in Education, 12(1), pp.177 -192.

[7] Gillander Gådin, K. \& Hammarstrom, A. 2000. Sexual harassment at school - a possible contributor to the higher degree of girls reporting psychological symptoms compared with boys in grade nine. European Journal of Public Health.

[8] AAUW 1993. 'Hostile hallways' The AAUW survey on sexual harassment in America"s schools. Washington, DC: American Association of UniversityWomen.

[9] Timmerman, G. 2002. A comparison between unwanted sexual behavior by teachers and by peers in secondary schools. Journal of Youth and Adolescent, 31(5), pp.397-404.

[10] Witkowska, E. 2005. Sexual harassment in schools Prevalence, structure and perceptions. National Institute for Working Life, 15(1), pp.78-85.

[11] Tinam, O. 2008. Gender Violence in Nigerian Schools. Gender \& HIV/AIDS Watch newsletter. , 1(1), pp.2-9.

[12] Zubairu, I., Muktar, H., Hadiza, S. \& Hamisu, M. 2011. Prevalence and correlates of gender-based violence among female university students in Northern Nigeri. African Journal of Reproductive Health, 15(3), pp.128-129

[13] Shaikh, M. 2000. Sexual harassment in medical profession: perspectives from Pakistan. Journal of the Pakistan Medical Association, 50, pp.130-131.

[14] Meyer, J. 2000. Nutshel Summaries of the root cuase of sexual assult. Nutshel: ECASA. Available at: http://www.ecasa.org.

[15] Catherine, H. \& Holly, K. 2011. Crossing the line: sexual harassment at school. Washington, DC: Amarica Assoiation of Univeristy Women foundation.

[16] Bagley, C., Bolitho, F. \& Bertrand, L. 1997. Sexual assault in school, mental health and suicidal behaviors in adolescent women in Canada. Journal of Adolescent Health, 32, pp.361366.

[17] Charol, S. \& Audrey, C. 1995. Sexual abuse of students by school personnel. Phi Delta Kappan, 76(7), pp.1-5. 